NISTIR 7341

\title{
An Assessment of a Possible Bench Scale Screening Protocol For Predicting Full-Scale Mattress Fire Behavior
}

Thomas J. Ohlemiller 

NISTIR 7341

\title{
An Assessment of a Possible Bench Scale Screening Protocol For Predicting Full-Scale Mattress Fire Behavior
}

\author{
Thomas J. Ohlemiller \\ Fire Research Division \\ Building and Fire Research Laboratory
}

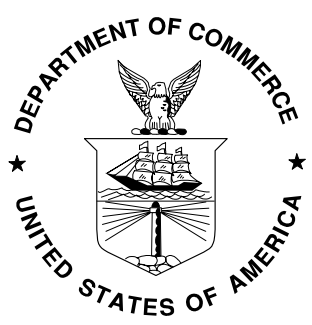

U.S. Department of Commerce Carlos M. Gutierrez, Secretary

Technology Administration Robert Cresanti, Under Secretary of Commerce for Technology 


\title{
An Assessment of a Possible Bench Scale Screening Protocol For Predicting Full-Scale Mattress Fire Behavior
}

\author{
T. J. Ohlemiller \\ National Institute of Standards and Technology \\ Building and Fire Research Laboratory
}

\begin{abstract}
This report summarizes a study of the feasibility of developing a bench-scale protocol for possible use in Code of Federal Regulations (CFR) 1633 (open flame) compliance testing of commercial mattress designs. It was shown that local resistance to the CFR 1633 gas burner exposure could successfully be done in one step with a composite consisting of a mattress top panel, tape edge seam and side panel (or analogous components for a foundation), rather than with separate tests for each component. A second type of test (with a different apparatus) is indicated for assessing resistance to commonly encountered, persistent mattress/foundation crevice flames which represent a different mode of mattress design vulnerability. An apparatus for this was developed but not systematically applied. Other vulnerability modes may require other tests. The real goal of bench-scale testing, faster and more economical assessments, is thus unlikely to be achieved and the best approach appears to be full-scale testing.
\end{abstract}

\section{Introduction}

The Consumer Product Safety Commission (CPSC) recently instituted a regulation (CFR 1633) that limits the consequences of open-flame ignition of beds. While the flaming ignition source most commonly encountered is small, i.e., match or candle size, the material ignited, bed clothing, results in a large fire insult to the mattress and foundation, which contain the bulk of the combustible materials. Thus the focus of the regulation is a pair of gas burners, mimicking the intensity of burning bed clothes, which are applied to the mattress and foundation. The regulation limits the ensuing peak heat release rate from this mattress/foundation combination within a particular time frame after ignition (30 min).

Enforcement of a national regulation of this nature implies both a considerable testing burden and the availability of specialized testing facilities. Compliance assessment is usually achieved by testing of random purchases of products from the open market. The enforcement process could potentially be appreciably facilitated by a small scale screening procedure that, at a minimum, cuts down on the full-scale testing burden.

Ideally the small scale screening procedure would produce results which correlate perfectly with the full-scale results of CFR 1633. Thus bench-scale measure(s) made on mattress and foundation materials or assemblies would quantitatively predict the peak heat release rate and the time to that peak when the mattress/foundation is subjected to the pair of gas burners.

Experience to date with the myriad subtleties which lead to mattress/foundation fires of varying sizes suggests that this ideal goal is simply not achievable both because of the nature of the fullscale test and because of the nature of the objects tested. However, a useful assessment of the 
fire resistance of some aspects of a given design can be achieved and this could reduce the amount of full scale testing required. Whether the use of bench-scale testing is ultimately more practical and economical is the subject of this study.

Although nearly all mattress designs responsive to CFR 1633 use barrier layers of varied types to obtain passing behavior, it is not sufficient to simply test the barrier itself for resistance to a CFR 1633 flame exposure. Other layers of the mattress are sometimes factored into the design to create passing behavior and, of course, seams are also essential elements.

The screening procedure originally proposed by NIST consisted of four separate steps. It is tacitly assumed that the mattress is a box spring design and the ultimate threat is flaming in the space defined by the springs. The first three steps looked for vulnerabilities in the panels and seams which form the outer envelope of a mattress or foundation. The fourth step attempted to assess the consequences of any vulnerability that is found. In the first two steps, material assemblies from each exposed ${ }^{1}$ surface or seams bonding two surfaces were subjected to small gas burners providing the virtual equivalent of the CFR 1633 burner flame exposures. Seams which pass by showing no flame penetration were still to be tested for residual strength in a third step. This step was prompted by early experience with a Sleep Products Safety Council (SPSC) mattress design which showed a marked tendency for a strong internal over-pressurization in full-scale tests with burning bed clothes; this over-pressure split its seams and led to a substantial fire [1]. Residual seam strength was intended as a measure of ability to resist such seam splitting. Finally, any surface or seam failure (indicated by flame penetration) in the first two gas burner exposure steps would prompt a fourth step. This step was intended to provide a measure of the peak size of fire the complete mattress/foundation assembly could yield. This utilized sections (roughly $30 \mathrm{~cm}$ wide ${ }^{2}$ ) of both mattress and foundation assemblies within a special holder. Peak heat release rate was to be measured approximately by peak mass loss rate from the combined assembly as it burned.

Had this multi-step screening procedure proved feasible, it would have implied a considerable testing burden of its own. Several changes and developments subsequently reduced it to two steps. Tests with several mattress designs, described in this report, have shown that substantially similar results can be obtained by combining steps one and two such that all mattress surfaces (or all foundation surfaces) are subjected to a gas burner in one step ${ }^{3}$. The requirement for step three (residual seam strength measurement) was obviated by the observation that no other mattress design tested by NIST in the last three years has exhibited the strong over-pressurizations shown by that early SPSC design ${ }^{4}$. The value of step four, burning of sections of the mattress and foundation assemblies, was called into question by the present author's limited attempts to implement it and the observation that its results were very likely to be strongly influenced by

\footnotetext{
1 "Exposed" here means a surface that would plausibly see flames from burning bed clothes. This includes the mattress top and sides as well as the foundation sides and a small upper peripheral portion of its top.

${ }^{2}$ The size was dictated by the goal of keeping the maximum fire heat release rate below about $50 \mathrm{~kW}$, an estimate of what could be handled safely by an overhead laboratory fume hood.

${ }^{3}$ What one gives up here is exposure of a substantial length of a tape edge seam. Instead, the tape edge is tested only along a length equal to the narrow width of the burner flames.

${ }^{4}$ Numerous weak over-pressurizations have been seen in full-scale tests with the CFR 1633 burners; none appeared to split any seams. The original SPSC design that was prone to strong over-pressurizations was not a practical commercial design for other reasons.
} 
subtle assembly and/or procedural details which could not be adequately controlled. In particular, the edges of the mattress and foundation sections were clearly going to pose very difficult-to-control fire paths that would strongly affect the fire size and thus invalidate the goal of the tests. Thus only the first two of the above four steps, which are combinable into one step, can be viewed as useful to mattress design flammability assessment.

The results of a comparison between the original two step procedure and the single step procedure for testing mattress or foundation surfaces and seams are presented in this report. Also presented is a comparison of the results of the single step procedure with full-scale CFR 1633 tests on eleven mattress designs.

An additional observation, made repeatedly in full-scale tests [2, 3] with more recent mattress/foundation designs responsive to CFR 1633 requirements, is that flame persistence in the mattress/foundation crevice is an indicator of potential failure. Small flames can persist at a given location along the crevice for times that exceed ten minutes and even longer at corners. This far exceeds the gas burner duration (70 s on the top of the mattress). What these flames lack in intensity (or heat flux imposed on adjacent surfaces), they can more than make up for in duration, provoking eventual burn-through of otherwise flame-resistant layers. This prompted the development of an additional test that seeks to mimic the threat from these weak, long-lived flames in the crevice. That test is also described here.

Rationale and Limitations of Bench-Scale Mattress Tests. The goal of these tests is to ascertain whether burn-through occurs in the mattress/foundation surfaces or seams being tested, either during the burner exposure or in any subsequent persistent burning of the sample materials. In the original four step procedure, each surface or seam was tested individually and so any weakness in each emerged in isolation. In the abbreviated, composite testing, the weakest surface or seam burns through first and stops the test; the test lasts no longer than the weakest component of the assembly.

In actual usage by CPSC, the test sample would have been cut from a mattress/foundation purchased from the open market. The bench-scale test seeks to determine how that mattress/foundation would perform if it were subjected to the CFR 1633 burners in a full scale test situation. A key issue is whether flames penetrate to the interior side of the sample during or after the burner exposure. To make this as realistic as possible, all layers of organic materials in the mattress/foundation construction are included as part of the tested sample. The interior of the sample then essentially represents the interior, typically spring-filled volume of the mattress or foundation. Flaming within either of these volumes in the full-scale mattress/foundation usually leads to a growing fire and probable ultimate failure of any reasonable mattress flammability criterion. (An exception to this is noted in the test results.)

This approach essentially assumes that all manufacturers will rely on fire barrier-like materials to protect the largely unchanged cushioning materials within their mattress/foundation designs. This has been the case for essentially all designs tested thus far. However, this approach, as developed here at least, would not work for designs which, instead of barriers, utilize flameretarded versions of the cushioning materials to limit fire growth. Burn-through of such 
materials could be a tolerable condition that did not lead to a large fire (if the materials were sufficiently fire-retarded).

Note that this particular type of bench-scale test can only follow what happens locally as a result of this type of burner exposure. The test is over when all burning of sample materials has ceased, typically in a few minutes. If this localized burning has not produced any flame penetration, the sample is, by this measure, evidently adequate to pass a CFR 1633 type test, regardless of the duration criterion that may apply in that type of full-scale test.

In a full-scale CFR 1633 type of test, the burner application is again local but the fire typically continues to spread to other areas of the mattress/foundation ${ }^{5}$. Frequently the early flames are minimal in size but remarkably persistent in time (especially in more adiabatic locations like the mattress/foundation crevice). Some of the heat from these flames accumulates within the mattress and foundation interior volumes. Often a consequence of that accumulation is a gradual strengthening of the fire continuing to spread elsewhere on the mattress or foundation. Subsequent fire development and the ultimate peak heat release rate of such a fire (within some time period) are highly dependent on details of materials and construction and are not predictable from the behavior exhibited during the burner exposure. The supplemental crevice test can at least pick up the vulnerability to burn-through after extended, low level flame exposure. This result again does not foretell the size of any subsequent fire but it does imply a greater likelihood of a fire of some significance.

\section{Description of the Test Apparatuses}

Surface Burner. Figure 1 is an overall view of the bench-scale gas burner assembly. Figure 2 is a schematic of the flow system that supplies propane to the burner head.

The burner head consists of a pair of T-burners, each made from $0.95 \mathrm{~cm}$ OD by $16.5 \mathrm{~cm}$ long stainless steel tubing having a straight-line series of 18 holes (nominally $0.13 \mathrm{~cm}$ diameter) for gas jets. The pair of tubes is held $5.4 \mathrm{~cm}$ apart with their gas jets pointed toward each other at an approximately $45^{\circ}$ angle. This pair of burner tubes serves the same function as the single horizontal burner tube in the CFR 1633 apparatus. Two tubes were used here because of the need to more uniformly expose the protrusive shape of a mattress or foundation tape edge in the original four step screening procedure ${ }^{6}$. The burner pair is held at a fixed distance $(20.3 \mathrm{~mm})$ above the test surface by means of a pair of stand-off feet. This distance, in combination with the gas flow rate to the burner pair, determines the heat flux which the burners impose on the test surface. Figure 3 shows the measured peak heat flux to the test surface as a function of transverse distance along a line near the center of the pair of burner tubes. The flux is measured with a $6 \mathrm{~mm}$ diameter, water-cooled, Schmidt-Boelter gage that yields a cold-wall total heat flux (convection plus radiation). Such flux measurements are generally accurate to better than $\pm 5 \%$

\footnotetext{
${ }^{5}$ In an actual bed fire the flames continue to spread elsewhere with more speed and vigor because of burning bed clothes.

${ }^{6}$ In the original four step procedure, the tape edge seams were tested with the seam parallel to the pair of burner tubes and halfway between (but below) them. The gas jets thus impinged on both sides of the tape edge as it protruded upward from the sample as it was laid out flat with mattress/foundation top and side surfaces in the same plane. One burner tube would suffice for the simplified test procedure discussed later in this report but a switchover to one tube would require extensive re-calibration of the heat flux from the burner.
} 
but the flux has a substantial high frequency noise level due to eddies in the turbulent diffusion flame provided by the gas burner. The flux tends to peak in the neighborhood of the impingement points of individual gas jets and a longitudinal scan along the burner assembly centerline shows three or four localized peaks (ca. $5 \mathrm{~mm}$ wide) near the burner center that are 10 $\%$ higher than the (78 to 80$) \mathrm{kW} / \mathrm{m}^{2}$ peak in Fig. 3. These fluxes (particularly the localized peaks) are higher than the nominal average flux of about $73 \mathrm{~kW} / \mathrm{m}^{2}$ reported for the horizontal CFR 1633 gas burner in Ref. 1. However, considerably more effort was put into flux vs. position characterization and spatial resolution in the present study ${ }^{7}$, as compared to Ref. 1 ; it is quite probable that these localized, jet-induced heat flux peaks exist also with the CFR 1633 burner. The spatial average of the peaks along the burner centerline, near the burner center, is about 75 $\mathrm{kW} / \mathrm{m}^{2}$.

This horizontal burner assembly lays atop the test surface with nominally the same downward force that is exerted by the horizontal burner in CFR 1633 (i.e., $170 \mathrm{~g}$ to $230 \mathrm{~g}, 6 \mathrm{oz}$ to $8 \mathrm{oz}$, applied on a total support foot area of $6.5 \mathrm{~cm}^{2}, 1 \mathrm{in}^{2}$ ). This force is applied so that the burner will follow any shrinkage of the heated test surface (in much the same manner burning bed clothes on top of a bed would do so). Here this is accomplished mechanically by mounting the burner assembly on a vertical guide rail and counterbalancing most of the burner assembly weight with a brass weight attached via a pair of cables running over a pulley system. There is more friction in this system than is desirable. To eliminate its effect on the net downward force of the burner, an electro-mechanical vibrator is attached to the support framework to prevent any sticking.

The duration of the flux impingement is determined by a time delay relay operating a solenoid valve in the gas supply line to the burner (Fig. 2). As with the CFR 1633 horizontal burner, the duration is set to $70 \mathrm{~s}$, a value inferred from burning bed clothes measurements in Ref. 1 .

In the original four step mattress screening procedure described in the Introduction, horizontal mattress or foundation surfaces were tested in a horizontal position with the above burner assembly. Vertical surfaces, however, were tested with a separate, much simpler vertical burner assembly using nominally the same heat flux conditions as those applied in CFR 1633 to such surfaces. A single T burner (same dimensions as the pair above) was rigidly mounted in a vertical orientation and positioned relative to the test surface with a single stand-off foot. Scans of this burner showed that it gave peak heat fluxes slightly higher than the nominal vertical burner values in Ref. 1 (ca. $58 \mathrm{~kW} / \mathrm{m}^{2}$ vs ca. $53 \mathrm{~kW} / \mathrm{m}^{2}$ ) along the upper $50 \%$ to $60 \%$ of its length. However, it gave quite high localized (few $\mathrm{mm}^{2}$ ) heat flux peaks due to non-diffused gas jets on its lower portion so that the section of the sample that would have been impinged by this lower portion of the burner was masked to preclude exposure to these excessive heat fluxes. As in CFR 1633, the vertical tests utilized only a 50 s exposure to the burner. As in the horizontal seam tests, a vertical seam was tested with that seam aligned parallel to the long

\footnotetext{
${ }^{7}$ A 6 mm diameter, Schmidt-Boelter, total heat flux gage was embedded flush into the surface of a water-cooled aluminum plate mounted, in turn, on a two-axis mechanical stage for scanning the gage position relative to the gas burner flames. The gage and plate were cooled with hot water to preclude false readings from water condensation. Flux measurements were made at a variety of gas flow and burner positioning conditions to find a combination nearest to the nominal results of Ref. 1
} 
direction of the burner so that several $\mathrm{cm}$ of the seam length were exposed to the $58 \mathrm{~kW} / \mathrm{m}^{2}$ flux peak.

As noted in the Introduction, tests were also performed using composite assemblies of all mattress or foundation surfaces. In this case a test sample consisted of a rectangular patch removed from the top and side of a mattress or foundation so as to include a section of the top, the tape edge seam and a portion of the side. The side portion in some cases included a vertical side seam. This assembly was laid out horizontally and tested flat using the horizontal burner. In such tests, the sample was rotated 90 degrees so that the burner flames were perpendicular to the tape edge seam but were parallel to and coincident with the "vertical" seam, if present. The tape edge is thus exposed only along a short section equal to the width of the burner flame (and to the peak flux only at one spot; see Fig. 3). Note that this achieves the goal of testing some portion of all elements of interest in a single exposure. However, the side surface (and its seam, if present) now sees the higher flux, longer duration condition seen in the alternative procedure above only by horizontal surfaces. This aspect of this composite test procedure is thus more severe than CFR 1633.

The emphasis on burn-through (or flame appearance on the interior side of the material assembly) as the ultimate outcome of these tests points to a need to assure against false flame penetrations as a result of a bypass around the sample edges. This issue is addressed by the design of the sample holder.

Sample Holder. The samples themselves are $38 \mathrm{~cm}$ by $23 \mathrm{~cm}$ while the flame exposed area is only about $16 \mathrm{~cm}$ by $7 \mathrm{~cm}$ to $8 \mathrm{~cm}$. The extra sample area serves two purposes. First, some of the additional peripheral material allows persistent localized flaming as in CFR 1633 and this may result in burn-through of materials weakened by the burner exposure. Second, the outer periphery of the sample provides a region intended to be a barrier to flames trying to work their to the sample rear side via the sample edges (an unrealistic path peculiar to testing sections of a mattress rather than the full mattress).

Figures 4a and 4b show two views of the sample holder. It is essentially a metal box with two compartments. The upper compartment holds the sample in its interior and, on its exterior, a simple pulley system for applying a fixed tension force (typically $2.0 \mathrm{~kg}$ ) in the plane of the sample. The sample rests on a peripheral, stainless steel "shelf" that is approximately $5 \mathrm{~cm}$ wide by $0.6 \mathrm{~cm}$ thick. The thickness is chosen to provide thermal heat sinking mass as part of the effort to suppress sample edge bypass flames.

The sample itself poses a substantial challenge here since it is not of uniform thickness in any embodiment that includes portions from two different surfaces of a mattress or foundation. The difference in thickness between a mattress top and mattress side can be many centimeters since the former includes cushioning layers of indefinite, but potentially large thickness ${ }^{8}$. As noted previously, the goal in the test is to lay the outer surface of the sample in a plane so that it bears a constant spatial relationship to the gas burner flames, thus fixing the heat flux this surface sees. The thin side of a non-uniform sample (e.g., the portion from the mattress side panel) is therefore

\footnotetext{
${ }^{8}$ The upper portion of the sample holder can accommodate sample thicknesses up to $15 \mathrm{~cm}$ (6 in).
} 
supported underneath by an appropriate thickness of rigid fiberglass batt on its periphery so the top surface of the test piece is flat across its full dimensions.

No pillowtop designs were included in any of the testing. It is not clear how one should apply the approach used here to the more complex geometry of a pillowtop though laying the pillow edge convolutions out flat may be the only viable alternative with this apparatus.

The top of the sample is covered on its periphery by a stainless steel frame, again about $5 \mathrm{~cm}$ wide, intended to be a heat sink to any flames moving toward the sample periphery. One straight side of the frame is a separate piece to accommodate the application of the tension force in the plane of the top surface of the sample. Thus opposite sides of this frame, unconnected to each other, each grip the sample top by means of thin spikes (1.3 $\mathrm{mm}$ dia by $13 \mathrm{~mm}$ long) protruding from their lower surfaces. A pair of cables attached near opposite ends of the straight frame side applies the tension weight evenly to the sample top.

The above system is well-suited to prevent flaming bypass of the sample edges provided that the sample top itself is in continuous contact with the upper peripheral frame. However, mattresses provide top surfaces of quite variable top surface relief, depending on the depth of the quilt layer. For most mattress designs tested it was necessary to supplement this system with pieces of ceramic wool filling, as much as possible, any gaps (due to the quilt pattern relief) between mattress surface and frame. Even so, mattress designs including a sacrificial layer of fiberfill above the barrier in the quilt layer could still allow flames to bore though the sample periphery and attempt to reach the sample rear by going around the sample edge. Adequate protection in this regard was a learning process that continued to adapt as new mattress designs were encountered. A fraction of the data obtained in this study was probably affected by this bypass burning problem; suspect data are flagged below.

The goal of the test is to see whether flames penetrate through the sample (not around its edges) to the lower portion of the sample holder box. Two redundant means of detecting flames are used. A pair of silicon photodiodes views this volume from opposite sides of the lower box. Their output is recorded by a computer. Alternatively, flame penetration can be seen visually by the test operator using a mirror that provides a wide view of the underside of the sample. To facilitate either detection mode, smoke accumulation in the box (caused by pyrolyzing sample materials) is kept to a minimum by a weak flow out an exhaust duct on the side of the lower section of the box. The time from the onset of the burner flame to first detection of flames in the lower portion of the box is recorded to the nearest second. Visual observation of burn-though times are accurate to about $\pm 1 \mathrm{~s}$. Due to the uneven nature of the lower surface of samples that include, for example, a portion of a mattress top and side, one or both of the photodiodes may not have a good view of penetrating flames. Visual observations by an experienced operator are more reliable once some of the pitfalls of this test are learned. ${ }^{9}$

Crevice Test. Figure 5 shows a picture of the crevice test assembly. Its goal is to subject sections of the mattress and adjacent foundation to the same level of flame intensity as was found in persistent crevice flames during full-scale mattress tests (38 kW/m² $\pm 6 \mathrm{~kW} / \mathrm{m}^{2}$; Ref. 3) for ten

\footnotetext{
${ }^{9}$ These include light coming through the sample when flames do not. This can happen in panel areas as well as at seams.
} 
minutes or more to ascertain whether this yields flaming on the mattress or foundation interior surfaces. The set-up recreates a crevice as follows. The material assemblies from mattress and foundation are each clamped over a basic shape-fixing structure that consists (for each assembly) of a piece of expanded stainless steel $(0.013 \mathrm{~cm}$ thick by $32 \mathrm{~cm}$ wide by $39 \mathrm{~cm}$ long with diamond-shaped openings $7 \mathrm{~cm}$ by $3 \mathrm{~cm}$ ) bent at $90^{\circ}$ so as to form a $16 \mathrm{~cm}$ high surface for a mattress or foundation side panel and a $23 \mathrm{~cm}$ deep section of mattress or foundation "top" surface. The various layers of materials are assembled in proper order and clamped onto the expanded metal to create $32 \mathrm{~cm}$ wide, appropriately-shaped sections of mattress and foundation. The mattress section is then clamped on top of the foundation section to create the desired crevice. When these two sections are clamped together, a $1.0 \mathrm{~cm}$ diameter tube, porous along one half of its circumference, is inserted ca. $5 \mathrm{~cm}$ into the crevice. This porous tube provides a means to inject a low flow of propane into the crevice which recreates the persistent, weak flames seen in full-scale mattress tests. Proper adjustment of the propane flow rate creates flames that hover inside the "mouth" of the crevice (after the ticking and any sacrificial layer outside the barrier layer are burned out). This propane substitutes for the unknown fuel gases coming from deeper layers in real mattress/foundation crevices. The crevice flame duration can then be made to be any desired value.

The crevice assembly is mounted on a simple framework that supports it above the bench top. The frame also supports two mirrors that allow the test operator to see the rear surfaces of both the mattress and foundation assemblies to detect any flame penetration.

As with the assemblies used in the preceding tests, there is a threat that flames will make their way to the "interior" by going around the periphery of the assembly. Here that problem is dealt with by using ceramic wool in the crevice area and aluminum foil wrapped over the outer edges.

Test Materials. Eleven mattress/foundation designs, previously tested with the CFR 1633 protocol, have been tested in the bench-scale burner exposure apparatus. These include three of the Sleep Products Safety Council (SPSC) designs described in Ref. 1, two other SPSC designs tested by the California Bureau of Home Furnishings, and 6 designs built for CPSC for which the full scale results are reported in Ref. 3. In the case of the SPSC designs, separate panels for bench-scale testing were made at the same time as the mattresses. For the CPSC designs the bench-scale samples were cut from spare mattress/foundation pairs.

All of these designs are based on the use of barrier materials between the external fabric layer (ticking) and the mattress/foundation interior. In most cases this barrier is a relatively thin layer just under the ticking. In some cases it is more diffuse, perhaps consisting of alternating layers of a charring fiber and normal polyurethane foam. The first three SPSC designs are summarized in Table 1, the second two in Table 2 and the six CPSC designs are summarized in Table 3 . In this report, the SPSC designs will be referred to as M1, M3, etc. and the CPSC designs as D1, D2, etc.

Table 4 summarizes the full scale peak heat release rate and time to that peak as found with the CFR 1633 test protocol for all of the above designs.

\section{Results and Discussion}


Surface Burner Tests. Comparison of Results for Two Sample Testing Modes. Recall that the original bench-scale testing mode called for testing each surface and seam separately while the revised protocol calls for testing all surfaces from a mattress or foundation at one time, as a composite that incorporates top and side surfaces held together by the manufacturer's original seams. In all cases mattresses and foundations are tested separately. Table 5 shows a comparison of the test results from these two testing modes for the five $\mathrm{M}$ designs.

In Table 5 the two columns on the left are results from the original protocol. Thus there are data reported for the measured burn-through times of each component (mattress top panel, mattress tape edge seam, mattress side panel plus the same three items for the foundation). A value of "none" means that no burn-through occurred over the burner exposure time plus a post exposure time that lasted out to 5 min or more (by which time all materials on the exposed surface -out to the sample holder frame- had usually self-extinguished).

In Table 5 the two columns on the right are the results for the testing of the composite (top panel, tape edge seam, side panel) from the mattress or foundation.

Comparison of the two modes of testing shows that there is never perfect agreement in the burnthrough times. Such agreement (even of replicate test averages) is not to be expected given the nature of the materials and the limited number of replicates. With the exception of the M3 design, there is however a general tendency for the results from the two testing modes to be similar in that both modes give roughly similar values for the shortest times to a burn-through. In looking at the data from the original protocol (left side of Table 5) it is the shortest time for any given component that is to be compared to the composite value on the right hand side. Thus the composite testing clearly gives much less data on the vulnerability of specific aspects of a design. The large savings in testing time in the composite tests is their main virtue.

The behavior of the M3 mattress composite in Table 5 is scattered but both modes of testing suggest a vulnerability of the design. In actual full scale tests this design generally looked much better than the Table 5 results imply. It gave large fires only late in tests in cases where the foundation wood got involved. The particular barrier used here, which is also the ticking in this design, can remain intact (no holes except a $2 \mathrm{~mm}$ to $3 \mathrm{~mm}$ gap along the tape edge seam) and still permit ignition of materials in the mattress interior. This intact barrier tends to limit the air supply to an internal fire (in a mattress; not necessarily so in a foundation) and keeps it very much limited in heat release rate. For such barriers, either test protocol used in Table 5 would raise questions. This simply means that the test, in these circumstances, is conservative and suggests a need for a full-scale test as a check.

Overall, the results in Table 5 indicate that the composite test is about as effective as the more time consuming tests of individual components of a design, That said, there is limited information in the Table 5 results. If one takes the conservative position that any indication of a burn-through is a sign of a need for further testing, then all of the designs in Table 5 need such testing; all gave at least one burn-through in both individual component and in composite tests. In fact the designs in Table 5 gave widely-varying full-scale performance in CFR 1633 tests; see Table 4. The time to burn-through seems to offer some hint about this, as discussed below. 
Table 6 summarizes composite test results for the six CPSC designs (D1 through D6 described in Table 3). All of these designs included a flame barrier and, except for D4, all did generally well in full-scale CFR 1633 testing (see Table 4). It should be noted here that designs D1 through D5 had continental foundations which means that the materials of the sidewall of the foundation continue unbroken onto the foundation top for 5 or more centimeters. This usually puts the foundation top panel materials so far back into the mattress/foundation crevice that they do not see the gas burner flames. Thus their poor performance (Designs D4 and D5) in the bench scale test is not likely to have an effect on full-scale performance.

Note that several of the burn-throughs listed in Table 6 appeared to be due to flame penetration around the edges of the sample assembly (denoted as a "frame bypass"). Again, precluding this type of misbehavior in the test is a learning process and it is most problematical with deeply quilted samples. One mattress failure of Design D3 was through the seam on the side panel; its wide opening suggests a failure to use the proper flame-resistant thread in that particular sample. At least one and possibly two of the failures of a Design D4 mattress sample (the first) was due to defective construction of the barrier layer; the relatively poor performance of this design in full-scale tests could have had the same cause, though its late occurrence argues against this.

Figures 6 and 7 show the full-scale peak heat release rate values obtained with the $\mathrm{M}$ series and $\mathrm{D}$ series designs (data from Table 4). The data are arranged in the order of smallest average value (over the replicates) to the largest. In Fig. 8 is a plot of a bench-scale measure on the M series - the time to sample burn-through. Comparison of Fig. 6 with Fig. 8 does suggest an approximate inverse correlation between peak heat release rate (HRR) and bench-scale burnthrough time. However, there is no sensible way to make a similar attempt at a correlation with the $\mathrm{D}$ series data in Table 6, especially after one removes the several points for which burnthrough occurred via a frame bypass. In fact, given that most current mattress designs employing flame barriers show greatly delayed heat release rate peaks that occur tens of minutes after gas burner exposure in CFR 1633, there is no physical reason to expect the burn-through time (if any) should correlate with peak HRR. The bench-scale burner exposure really only gives a measure of whether a mattress design is immediately vulnerable to local gas burner exposure. If it is, of course, the design is fatally flawed. This bench-scale test cannot predict the ultimate fate of a mattress tens of minutes later as it is subjected to persistent propagating flames, especially persistent flames in the mattress/foundation crevice.

Other Tests. The crevice test (Fig. 5) was conceived as a complement to the above test. It attempts to pick up the most likely (based on several years of test experience) longer term vulnerability of a mattress design, i.e., one that shows up after ten or more minutes of persistent weak flaming in the mattress/foundation crevice. It is certainly a preferable alternative to the original fourth test proposed as part of a screening protocol. That fourth test, mentioned in the Introduction, attempted to reconstruct and burn a section of the mattress and foundation to get a measure (via rate of weight loss) of the potential peak HRR that the sample materials could give after local failure of a seam or barrier layer. Only limited work was done with that test because it was evident that the burning process in the test apparatus was influenced entirely too much by the fact that the sample was a finite section (roughly $30 \mathrm{~cm}$ wide) whose edges were strongly affecting the fire behavior. The results would thus reflect more of the interaction of the materials 
with the apparatus rather than giving a true measure of expected behavior from a full-scale mattress/foundation fire test.

The crevice test has a more modest goal - to ascertain whether internal ignition will occur through either the mattress or foundation outer layers as a result of an extended weak flame exposure. The test was developed to the point where it appeared to be capable of achieving its goal. However, it was not systematically applied to any set of mattress designs before this study was ended. Thus its viability in this regard must be viewed as unproven.

\section{Summary and Conclusions.}

The goal of a bench-scale test protocol which predicts the CFR 1633 behavior of a mattress/foundation design must be viewed as somewhat quixotic. The actual behavior of real mattresses, especially those with some level of flaming resistance built in, is highly varied and prone to evolve slowly tens of minutes after the brief gas burner exposure. At this point it is clear that not all of the physical processes that dictate ultimate fire size are fully understood. The test procedures developed here aimed at looking first at the immediate response of the assembly of mattress or foundation materials to gas burner exposure - the possibility that the burner flames will yield a local penetration to the interior where they could be expected to cause a serious fire. Tests of several designs were ambiguous about the relation between local burn-through time and overall full-scale mattress fire behavior. Furthermore, most of the designs with fire barriers did not yield any burn-throughs; sporadic "frame bypass" events in the tests added an element of unreliability that could only be overcome by re-testing with ever greater precautions and protections of the sample edges. Experience with full-scale mattresses points to the need for a complementary crevice test to ascertain the vulnerability to a separate mode of potential failure. More recent experience with certain full-scale mattress designs points to yet another potential failure mode - barrier splitting due to shrinkage. It is impractical and uneconomical to develop separate bench-scale tests for all possible failure modes in mattress designs. Thus, at this point, it appears that the only practical solution for assessing the compliance of mattress designs with CFR 1633 is full-scale testing. 


\section{Acknowledgements}

Randy Shields of NIST was instrumental in all of the set-up and testing of the apparatuses discussed here. Gail Stafford and Drew Bernatz of CPSC became very proficient with the panel testing apparatus and provided most of the mattress design test work reported here.

This work was sponsored by the Consumer Product Safety Commission. The content of this report does not necessarily reflect the views of the Commission nor does the mention of trade names, commercial products or organizations imply endorsement by the Commission or the USFA.

\section{References}

1) Ohlemiller, T., Shields, J., McLane, R. and Gann, R., "Flammability Assessment Methodology for Mattresses," National Institute of Standards and Technology NISTIR 6497, June, 2000

2) Ohlemiller, T. and Gann, R., "Effect of Bed Clothes Modifications on Fire Performance of Bed Assemblies,” NIST Technical Note 1446, February, 2003

3) Ohlemiller, T., "Flammability Tests of Full-Scale Mattresses: Gas Burners versus Burning Bed Clothes,” NISTIR 7006, July, 2003 
Table 1. Component Materials in SPSC Mattress Designs (Refer to Figure 5 for Component Locations)

\begin{tabular}{|c|c|c|c|}
\hline & M 1 & M 3 & M 5 \\
\hline Ticking & Std. Damask & $\begin{array}{l}\text { Combined } \\
\text { fabric/barrier }\end{array}$ & MVSS 302 damask \\
\hline Quilt & $\begin{array}{l}19 \mathrm{~mm}(3 / 4 \mathrm{in}) \\
\text { std. } \mathrm{PU}^{10} \text { foam } \\
\left(19.2 \mathrm{~kg} / \mathrm{m}^{3} \text {, }\right. \\
\left.1.2 \mathrm{lb} / \mathrm{ft}^{3}\right) \text { in } \\
\text { quilt }\end{array}$ & $\begin{array}{l}\text { Same as Mattress } \\
\# 1\end{array}$ & $\begin{array}{l}19 \mathrm{~mm}(3 / 4 \text { in) TB } \\
117 \text { PU foam in } \\
\text { quilt }\end{array}$ \\
\hline Topper Pad & $\begin{array}{l}25.4 \mathrm{~mm}(1 \mathrm{in}) \\
\text { std. PU foam } \\
\left(19.2 \mathrm{~kg} / \mathrm{m}^{3} \text {, }\right. \\
\left.1.2 \mathrm{lb} / \mathrm{ft}^{3}\right)\end{array}$ & $\begin{array}{l}\text { Same as Mattress } \\
\# 1\end{array}$ & $\begin{array}{l}12.7 \mathrm{~mm}(0.5 \mathrm{in}) \\
\mathrm{TB} 117 \mathrm{PU} \text { foam } \\
\left(19.2 \mathrm{~kg} / \mathrm{m}^{3}, 1.2\right. \\
\left.\mathrm{lb} / \mathrm{ft}^{3}\right) \text { over } 1.1 \\
\mathrm{~kg} / \mathrm{m}^{2}\left(3.5 \mathrm{oz} / \mathrm{ft}^{2}\right) \\
\text { boric acid treated } \\
\text { cotton batt }\end{array}$ \\
\hline Insulator & $\begin{array}{l}\text { Thermo-plastic } \\
\text { Mesh Pad }\end{array}$ & $\begin{array}{l}\text { Thermo-plastic } \\
\text { Mesh Pad }\end{array}$ & $\begin{array}{l}\text { Thermo-plastic } \\
\text { Mesh Pad }\end{array}$ \\
\hline Spring Unit & $\begin{array}{l}\text { Twin } \\
\text { Innerspring }\end{array}$ & Twin Innerspring & Twin Innerspring \\
\hline $\begin{array}{l}\text { Mattress } \\
\text { Border }\end{array}$ & $\begin{array}{l}6 \mathrm{~mm}(1 / 4 \mathrm{in}) \\
\text { std. PU foam } \\
\left(19.2 \mathrm{~kg} / \mathrm{m}^{3}\right. \\
\left.1.2 \mathrm{lb} / \mathrm{ft}^{3}\right) \\
\text { under std. } \\
\text { Damask }\end{array}$ & $\begin{array}{l}\text { Same as Mattress } \\
\# 1\end{array}$ & $\begin{array}{l}\text { Boric acid treated } \\
\text { cotton batt under } \\
\text { MVSS } 302 \text { damask }\end{array}$ \\
\hline Thread & Standard & $\begin{array}{l}\text { Combustion } \\
\text { modified }\end{array}$ & Standard \\
\hline $\begin{array}{l}\text { Foundation } \\
\text { Border }\end{array}$ & $\begin{array}{l}\text { Same as } \\
\text { mattress }\end{array}$ & Same as mattress & Same as mattress \\
\hline $\begin{array}{l}\text { Foundation } \\
\text { Top Pad }\end{array}$ & $\begin{array}{l}0.62 \mathrm{~kg} / \mathrm{m}^{2}(2 \\
\left.\mathrm{oz} / \mathrm{ft}^{2}\right) \\
\text { polyester fiber } \\
\text { pad }\end{array}$ & $\begin{array}{l}0.62 \mathrm{~kg} / \mathrm{m}^{2}(2 \\
\text { oz/ft }) \text { polyester } \\
\text { fiber pad }\end{array}$ & $\begin{array}{l}0.62 \mathrm{~kg} / \mathrm{m}^{2}(2 \\
\text { oz/ft' }) \text { polyester } \\
\text { fiber pad }\end{array}$ \\
\hline
\end{tabular}

${ }^{10} \mathrm{PU}=$ polyurethane 
Table 2. Second Set of SPSC Designs

\begin{tabular}{|l|l|l|}
\hline & \multicolumn{1}{|c|}{ M6 } & \multicolumn{1}{|c|}{ M7 } \\
\hline Ticking & Class “B” & Class “B” \\
\hline Quilt & $\begin{array}{l}\text { Charring fiber A over 1 oz } \\
\text { PE } \\
\text { PU foam }\end{array}$ & $\begin{array}{l}\text { Charring fiber B over 2.5 cm } \\
(1 \text { in) PU foam }\end{array}$ \\
\hline Upholstery & $\begin{array}{l}2.5 \mathrm{~cm}(1 \text { in) PU foam (1.2 } \\
\text { pcf) }\end{array}$ & $\begin{array}{l}2.5 \mathrm{~cm} \text { (1 in) PU foam (1.4 } \\
\text { pcf) }\end{array}$ \\
\hline Insulator & Std Shoddy Pad & Std Shoddy Pad \\
\hline Spring Unit & Steel Coil Spring & Steel Coil Spring \\
\hline Border & $\begin{array}{l}\text { Charring fiber A under } \\
\text { Ticking }\end{array}$ & $\begin{array}{l}\text { Charring fiber layer plus } \\
\text { Charring fiber B }\end{array}$ \\
\hline Thread & Aramid & Combustion modified \\
\hline Closing Tape & Std PE & Std PE \\
\hline Fdn Ticking & Same as mattress & Same as mattress \\
\hline Fdn Filler Cloth & Non-Skid & Non-Skid \\
\hline Fdn Spring Unit & $\begin{array}{l}\text { Semi-flex on wood frame } \\
\text { w/slats }\end{array}$ & $\begin{array}{l}\text { Semi-flex on wood frame } \\
\text { w/slats }\end{array}$ \\
\hline Fdn Thread & Aramid & Combustion modified \\
\hline Fdn Border Style & Continental border & Continental border \\
\hline & & \\
\hline & & \\
\hline
\end{tabular}

${ }^{11} \mathrm{PE}=$ polyester 
Table 3. Nominal Composition of CPSC Mattress/Foundation Designs ${ }^{12}$

\begin{tabular}{|c|c|c|c|c|c|c|}
\hline & Design 1 & Design 2 & Design 3 & Design 4 & Design 5 & Design 6 \\
\hline $\begin{array}{l}\text { Mattress } \\
\text { Ticking }\end{array}$ & $\begin{array}{l}\text { Class B } \\
\text { damask } 1\end{array}$ & $\begin{array}{l}\text { Class B } \\
\text { damask } 2\end{array}$ & Class B & $\begin{array}{l}\text { Class B } \\
\text { PE/Cotton }\end{array}$ & $\begin{array}{l}65 \% \\
\text { Cotton/35 \% } \\
\text { PE }\end{array}$ & $\begin{array}{l}\mathrm{PE}, \mathrm{PP}, \\
\text { cotton } \\
\text { blend }\end{array}$ \\
\hline Quilt Layer & $\begin{array}{l}\text { Charring } \\
\text { barrier } \\
\text { fabric A } \\
\text { over } 19 \\
\text { mm }(0.75 \\
\text { in) PU } \\
\text { foam }\end{array}$ & $\begin{array}{l}\text { Charring } \\
\text { barrier } \\
\text { fabric B } \\
\text { over } 19 \\
\text { mm }(0.75 \\
\text { in) PU } \\
\text { foam }\end{array}$ & $\begin{array}{l}\text { FR cotton } \\
\text { over } 13 \\
\text { mm }(0.5 \\
\text { in) PU } \\
\text { foam }\end{array}$ & $\begin{array}{l}\text { Charring } \\
\text { barrier } \\
\text { fabric } D \\
\text { over } 25 \\
\text { mm (1 in) } \\
\text { soft PU } \\
\text { foam }\end{array}$ & 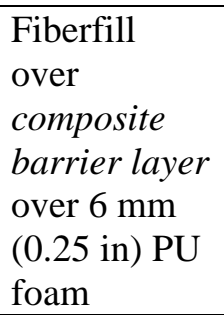 & $\begin{array}{l}\text { Charring } \\
\text { fiberfill } \\
\text { blend over } \\
9.5 \mathrm{~mm} \\
(0.38 \mathrm{in}) \\
\text { PU foam }\end{array}$ \\
\hline $\begin{array}{l}\text { Layers on } \\
\text { Springs }\end{array}$ & $\begin{array}{l}25 \mathrm{~mm} \text { (1 } \\
\text { in) PU } \\
\text { foam over } \\
\text { PP net }\end{array}$ & $\begin{array}{l}25 \mathrm{~mm}(1 \\
\text { in) PU } \\
\text { foam over } \\
\text { PP net }\end{array}$ & $\begin{array}{l}\text { FR cotton } \\
\text { over } 25 \\
\text { mm (1 in) } \\
\text { PU foam } \\
\text { over } \\
\text { needled } \\
\text { FR cotton } \\
(6 \mathrm{~mm})\end{array}$ & $\begin{array}{l}19 \mathrm{~mm} \\
(0.75 \mathrm{in}) \\
\text { PU foam in } \\
\text { two layers } \\
\text { over } \\
\text { shoddy pad }\end{array}$ & $\begin{array}{l}\text { Two } 25 \text { mm } \\
\text { layers of } \\
\text { undescribed } \\
\text { materials }\end{array}$ & $\begin{array}{l}\text { FR cotton } \\
\text { over } 13 \\
\text { mm (0.5 in) } \\
\text { PU foam } \\
\text { over } \\
\text { blended } \\
\text { fiber pad }\end{array}$ \\
\hline $\begin{array}{l}\text { Mattress } \\
\text { Border }\end{array}$ & $\begin{array}{l}\text { Same as } \\
\text { quilt layer } \\
\text { but } \\
\text { without } \\
\text { PU foam }\end{array}$ & $\begin{array}{l}\text { Same as } \\
\text { quilt layer } \\
\text { but } \\
\text { without } \\
\text { PU foam }\end{array}$ & $\begin{array}{l}\text { Quilted } \\
\text { FR cotton }\end{array}$ & $\begin{array}{l}\text { Lighter } \\
\text { weight } \\
\text { charring } \\
\text { barrier } \\
\text { fabric D } \\
\text { inside } \\
\text { ticking }\end{array}$ & $\begin{array}{l}\text { Composite } \\
\text { barrier layer } \\
\text { inside } \\
\text { ticking; } 6 \\
\text { mm PU } \\
\text { foam behind } \\
\text { barrier }\end{array}$ & $\begin{array}{l}\text { Lighter } \\
\text { weight } \\
\text { charring } \\
\text { fiberfill } \\
\text { blend under } \\
\text { ticking }\end{array}$ \\
\hline $\begin{array}{l}\text { Foundation } \\
\text { Top }\end{array}$ & $\begin{array}{l}\text { Std non- } \\
\text { skid fabric } \\
\text { over } \\
\text { charring } \\
\text { barrier } \\
\text { fabric C }\end{array}$ & $\begin{array}{l}\text { Std non- } \\
\text { skid fabric } \\
\text { over } \\
\text { charring } \\
\text { barrier } \\
\text { fabric } C\end{array}$ & $\begin{array}{l}\text { Cover } \\
\text { fabric } \\
\text { over two } \\
6 \mathrm{~mm} \\
\text { layers of } \\
\text { FR cotton }\end{array}$ & $\begin{array}{l}\text { Cover } \\
\text { fabric over } \\
\text { "std } 2 \text { oz } \\
\text { insulator" } \\
\text { pad }\end{array}$ & $\begin{array}{l}\text { Composite } \\
\text { barrier layer } \\
\text { under cover } \\
\text { fabric }\end{array}$ & $\begin{array}{l}\text { Cover } \\
\text { fabric over } \\
\text { FR cotton } \\
\text { over } \\
\text { blended } \\
\text { fiber pad }\end{array}$ \\
\hline $\begin{array}{l}\text { Foundation } \\
\text { Border }\end{array}$ & $\begin{array}{l}\text { Same as } \\
\text { mattress } \\
\text { border; ca. } \\
95 \mathrm{~mm} \\
\text { wide } \\
\text { Cont'l }\end{array}$ & $\begin{array}{l}\text { Same as } \\
\text { mattress } \\
\text { border; ca. } \\
95 \mathrm{~mm} \\
\text { wide } \\
\text { Cont'l }\end{array}$ & $\begin{array}{l}\text { Same as } \\
\text { mattress } \\
\text { border; } \\
\text { ca. } 70 \\
\text { mm wide } \\
\text { Cont'l }\end{array}$ & $\begin{array}{l}\text { Same as } \\
\text { mattress } \\
\text { border; ca. } \\
90 \mathrm{~mm} \\
\text { wide } \\
\text { Cont'l }\end{array}$ & $\begin{array}{l}\text { Composite } \\
\text { barrier layer } \\
\text { under } \\
\text { ticking; ca } \\
65 \mathrm{~mm} \\
\text { Cont'l }\end{array}$ & $\begin{array}{l}\text { Same as } \\
\text { mattress } \\
\text { border (but } \\
\text { barrier is } \\
\text { apparently } \\
\text { lighter) }\end{array}$ \\
\hline Seams & $\begin{array}{l}\text { All fire } \\
\text { resistant } \\
\text { thread }\end{array}$ & $\begin{array}{l}\text { All fire } \\
\text { resistant } \\
\text { thread }\end{array}$ & $\begin{array}{l}\text { All fire } \\
\text { resistant } \\
\text { thread }\end{array}$ & $\begin{array}{l}\text { All fire } \\
\text { resistant } \\
\text { thread }\end{array}$ & $\begin{array}{l}\text { All fire } \\
\text { resistant } \\
\text { thread }\end{array}$ & $\begin{array}{l}\text { All fire } \\
\text { resistant } \\
\text { thread }\end{array}$ \\
\hline
\end{tabular}

\footnotetext{
${ }^{12}$ Abbreviations: $\mathrm{PU}=$ polyurethane; $\mathrm{PP}$ = polypropylene; $\mathrm{PE}$ = polyester; $\mathrm{FR}$ = fire-retarded; Cont' $\mathrm{l}$ = continental border. All fire resistant features indicated in italics.
} 
Table 4. Summary of Average Peak HRR and Time to Peak In Full-Scale CFR 1633 Tests of Mattress/Foundations

\begin{tabular}{|c|c|c|}
\hline Matt/Fdn Designation & Peak HRR (kW) $^{\mathbf{1 3}}$ & Time to HRR Pk (s) \\
\hline M1 & $930^{14}$ & 200 \\
\hline M3 & 35 & 0 \\
\hline M5 & $420^{15}$ & 970 \\
\hline M6 & & 1900 \\
\hline M7 & ca. $2000^{16}$ & 30 \\
\hline D1 & 22 & $0,0,0$ \\
\hline D2 & $0,0,0$ & N. A. $^{17}, 1200$, N. A. \\
\hline D3 & $20,35,20$ & 3525, N. A., N. A. \\
\hline D4 & $455,20,20$ & $3250,3310,3545$ \\
\hline D5 & $1245,995,870$ & 900, N. A., N. A. \\
\hline D6 & $50,20,20$ & N. A., 2780, N. A. \\
\hline & $20,490,20$ & \\
\hline & &
\end{tabular}

\footnotetext{
${ }^{13}$ For all of the M series designs, the results for peak HRR and time to peak are the average of two tests (M1, M3, M5) or three tests (M6 except as noted below and M7). For the D designs, individual test results are listed.

${ }^{14}$ Data obtained at a commercial testing lab. There were indications from later NIST tests of this design that the peak HRR here was probably about $50 \%$ larger than this but was underestimated due to smoke spillage from the hood.

${ }^{15}$ This design was quite variable in performance in various tests and could give two appreciable heat release peaks, sometimes as large as $600 \mathrm{~kW}$

${ }^{16}$ Tested in a room at CBHF. These tests had to be terminated before they peaked but one of three exceeded 2.6 MW; the other two were stopped before reaching $1 \mathrm{MW}$. The room environment can be expected to have boosted the peak HRR values above those to be seen in an open hood, which was the condition for all of the other tests reported here.

${ }^{17} \mathrm{~N}$. A. here means that no time to peak could be measured since the peak, reported as $20 \mathrm{~kW}$, was below the sensitivity of the hood system used.
} 
Table 5

Comparison of Test Results for Two Sampling Modes

Left Two Columns: Surfaces/Seams Tested Individually

Right Two Columns: Top/Seam/Side Tested as Unit

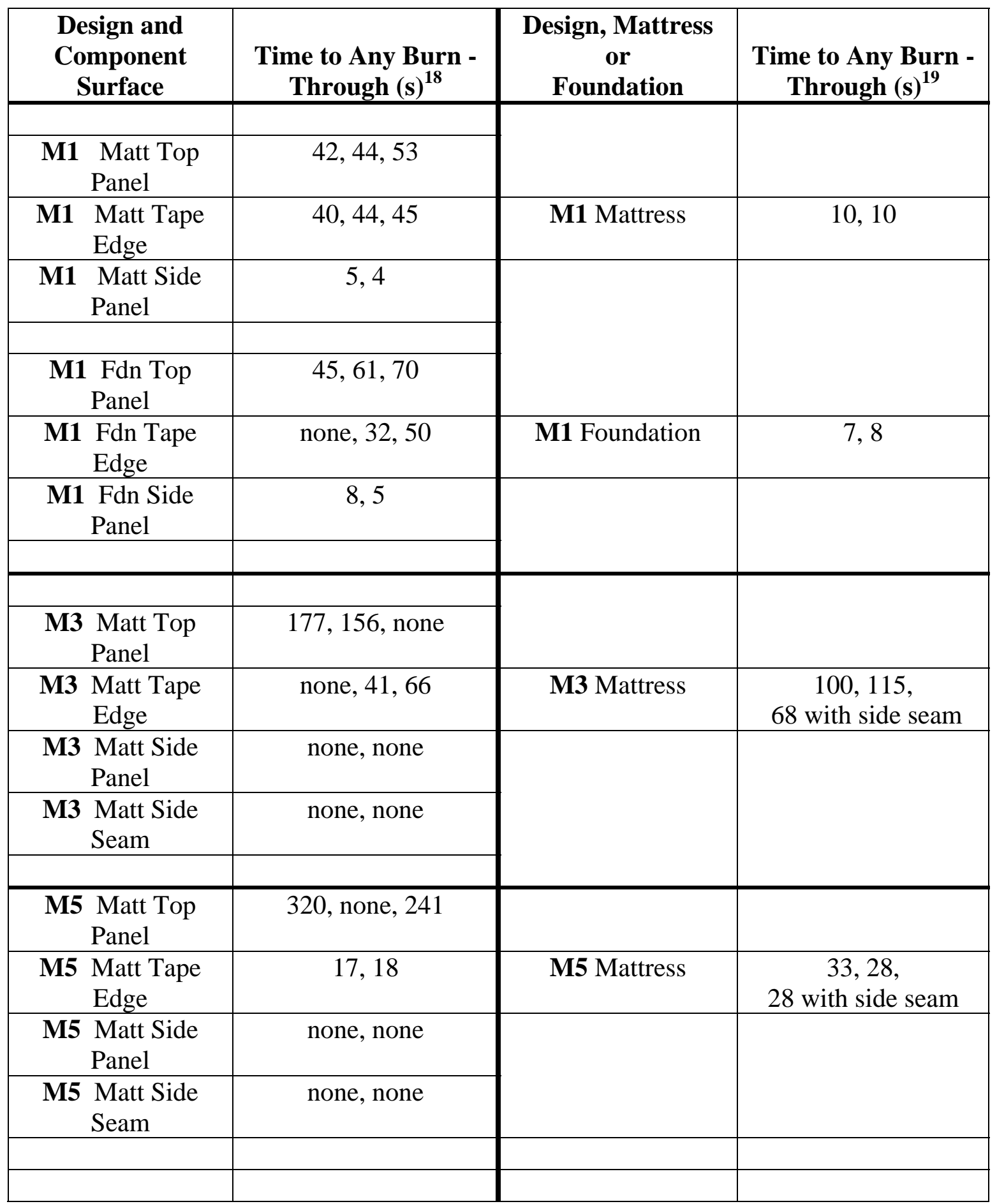

\footnotetext{
${ }^{18}$ Horizontal surfaces tested at higher flux for $70 \mathrm{~s}$; Vertical surfaces tested at lower flux for $50 \mathrm{~s}$

${ }^{19}$ All assemblies tested at higher flux for $70 \mathrm{~s}$
} 


\begin{tabular}{|c|c|c|c|}
\hline $\begin{array}{c}\text { Design and } \\
\text { Component } \\
\text { Surface }\end{array}$ & $\begin{array}{c}\text { Time to Any Burn - } \\
\text { Through (s) }\end{array}$ & $\begin{array}{c}\text { Design, Mattress } \\
\text { or } \\
\text { Foundation }\end{array}$ & $\begin{array}{c}\text { Time to Any Burn - } \\
\text { Through (s) }\end{array}$ \\
\hline $\begin{array}{c}\text { M5 Fdn Top } \\
\text { Panel }\end{array}$ & 58, 53, 75 & M5 Foundation & 31,21 \\
\hline $\begin{array}{c}\text { M5 Fdn Tape } \\
\text { Edge }\end{array}$ & 20, 12, none & & \\
\hline $\begin{array}{c}\text { M5 Fdn Side } \\
\text { Panel }\end{array}$ & none, none & & \\
\hline $\begin{array}{c}\text { M5 Fdn Side } \\
\text { Seam }\end{array}$ & none, none & & \\
\hline
\end{tabular}

${ }^{20}$ Horizontal surfaces tested at higher flux for $70 \mathrm{~s}$; Vertical surfaces tested at lower flux for $50 \mathrm{~s}$

${ }^{21}$ All assemblies tested at higher flux for $70 \mathrm{~s}$ 
Table 5, Cont'd

Comparison of Test Results for Two Sampling Modes

Left Two Columns: Surfaces/Seams Tested Individually

Right Two Columns: Top/Seam/Side Tested as Composite

\begin{tabular}{|c|c|c|c|}
\hline $\begin{array}{c}\text { Design and } \\
\text { Component } \\
\text { Surface } \\
\end{array}$ & $\begin{array}{c}\text { Time to Any Burn } \\
\text { Through }^{22} \text { (s) }\end{array}$ & $\begin{array}{c}\text { Design, Mattress } \\
\text { or } \\
\text { Foundation } \\
\end{array}$ & $\begin{array}{c}\text { Time to Any Burn - } \\
\text { Through (s) }\end{array}$ \\
\hline $\begin{array}{l}\text { M6 Matt Top } \\
\text { Panel }\end{array}$ & 378, none, none & & \\
\hline $\begin{array}{l}\text { M6 Matt Tape } \\
\text { Edge }\end{array}$ & 97,99 & M6 Mattress & $\begin{array}{c}75,71, \\
77 \text { with side seam }\end{array}$ \\
\hline $\begin{array}{l}\text { M6 Matt Side } \\
\text { Panel }\end{array}$ & none, none & & \\
\hline $\begin{array}{l}\text { M6 } \text { Matt Side } \\
\text { Seam }\end{array}$ & 135, none & & \\
\hline & & & \\
\hline $\begin{array}{l}\text { M7 Matt Top } \\
\text { Panel }\end{array}$ & (406), none, none & & \\
\hline $\begin{array}{l}\text { M7 Matt Tape } \\
\text { Edge }\end{array}$ & none, none & M7 Mattress & $\begin{array}{c}\text { none, none, } \\
158 \text { with side seam }\end{array}$ \\
\hline $\begin{array}{l}\text { M7 Matt Side } \\
\text { Panel }\end{array}$ & none, none, & & \\
\hline $\begin{array}{l}\text { M7 Matt Side } \\
\text { Seam }\end{array}$ & none, none & & \\
\hline $\begin{array}{l}\text { M7 Fdn Top } \\
\text { Panel }\end{array}$ & $39,39,35$ & & \\
\hline $\begin{array}{l}\text { M7 Fdn Tape } \\
\text { Edge }\end{array}$ & $75,13,9$ & M7 Foundation & 31,32 \\
\hline $\begin{array}{l}\text { M7 Fdn Side } \\
\text { Panel }\end{array}$ & none, none & & \\
\hline $\begin{array}{l}\text { M7 Fdn Side } \\
\text { Seam }\end{array}$ & none, none & & \\
\hline & & & \\
\hline
\end{tabular}

${ }^{22}$ Horizontal surfaces tested at higher flux for $70 \mathrm{~s}$; Vertical surfaces tested at lower flux for $50 \mathrm{~s}$

${ }^{23}$ All assemblies tested at higher flux for $70 \mathrm{~s}$ 
Table 6. Summary of Composite Bench-Scale Test Results for D Series ${ }^{24}$

\begin{tabular}{|c|c|c|}
\hline Matt/Fdn Design & Time to Any Burn-Through (s) & Comment \\
\hline D1 Mattress & $(78)$ & post-exposure burn-through was possible frame bypass \\
\hline D1 Mattress & No Burn Through & all flaming out at $4 \mathrm{~min} 30 \mathrm{~s}$; smoke/smol. until 5 min $55 \mathrm{~s}$ \\
\hline D1 Mattress & No Burn Through & all flaming out at $4 \mathrm{~min} 15 \mathrm{~s}$ \\
\hline $\begin{array}{c}\text { D1 Mattress } \\
\text { With Vertical Seam }\end{array}$ & No Burn Through & all flaming out at $1 \mathrm{~min} 26 \mathrm{~s}$; smoke/smol. until $3 \mathrm{~min} 30 \mathrm{~s}$ \\
\hline D1 Foundation & No Burn Through & all flaming out at $2 \min 39 \mathrm{~s}$ \\
\hline D1 Foundation & No Burn Through & all flaming out at 2 min $50 \mathrm{~s}$; smoke/smol. until 3 min $15 \mathrm{~s}$ \\
\hline D1 Foundation & No Burn Through & all flaming out at 5 min $53 \mathrm{~s}$; smoke/smol. until 6 min $14 \mathrm{~s}$ \\
\hline $\begin{array}{l}\text { D1 Foundation } \\
\text { With Vertical Seam }\end{array}$ & No Burn Through & all flaming out at 2 min $46 \mathrm{~s}$; smoke/smol. until 3 min $45 \mathrm{~s}$ \\
\hline D2 Mattress & No Burn Through & all flaming out at 3 min $50 \mathrm{~s}$; matt smolder until 6 min $10 \mathrm{~s}$ \\
\hline D2 Mattress & No Burn Through & all flaming out at 7 min $31 \mathrm{~s}$; matt smolder until $16 \min 50 \mathrm{~s}$ \\
\hline D2 Mattress & No Burn Through & all flaming out at 4 min $43 \mathrm{~s}$; side smolder until 4 min $45 \mathrm{~s}$ \\
\hline $\begin{array}{c}\text { D2 Mattress } \\
\text { With Vertical Seam }\end{array}$ & 190 & $\begin{array}{l}\text { post-exposure flames penetrated vertical seam but left the } \\
\text { stitching intact across the seam }\end{array}$ \\
\hline D2 Foundation & No Burn Through & all flaming out at 3 min $58 \mathrm{~s}$; side smolder until 4 min $38 \mathrm{~s}$ \\
\hline D2 Foundation & No Burn Through & all flaming out at 3 min $41 \mathrm{~s}$; side smolder until 4 min $49 \mathrm{~s}$ \\
\hline D2 Foundation & No Burn Through & all flaming out at 4 min $12 \mathrm{~s}$; side smolder until 6 min $10 \mathrm{~s}$ \\
\hline
\end{tabular}

\footnotetext{
${ }^{24}$ Burner exposure, in all cases, was 70 seconds.
} 
Table 6, Cont'd. Summary of Composite Bench-Scale Test Results for D Series ${ }^{25}$

\begin{tabular}{|c|c|c|}
\hline Matt/Fdn Design & Time to Any Burn-Through (s) & Comment \\
\hline D3 Mattress & No Burn Through & all flaming out at 7 min 30s; smoke/smol. until $10 \min 9 \mathrm{~s}$ \\
\hline D3 Mattress & $(200 \mathrm{~s})$ & post-exposure burn through was probably an edge bypass \\
\hline D3 Mattress & No Burn Through & all flaming out at 6 min $19 \mathrm{~s}$; smoke/smol. until 9 min $7 \mathrm{~s}$ \\
\hline $\begin{array}{c}\text { D3 Mattress } \\
\text { With Vertical Seam }\end{array}$ & 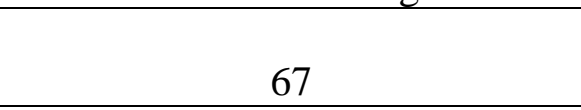 & vertical seam opened wide \\
\hline D3 Foundation & No Burn Through & all flaming out at $1 \mathrm{~min} 32 \mathrm{~s}$; smoke/smol. until $5 \min 45 \mathrm{~s}$ \\
\hline D3 Foundation & No Burn Through & all flaming out at 2 min $1 \mathrm{~s}$; smoke/smol. until 4 min $5 \mathrm{~s}$ \\
\hline D3 Foundation & No Burn Through & all flaming out at 2 min $6 \mathrm{~s}$; smoke/smol. until 5 min $8 \mathrm{~s}$ \\
\hline $\begin{array}{c}\text { D3 Foundation } \\
\text { With Vertical Seam } \\
\end{array}$ & No Burn Through & all flaming out at 3 min; smoke/smol. until 12 min $35 \mathrm{~s}$ \\
\hline D4 Mattress & $(143)$ & post-expos. flames penetrated mattress top; possible top barrier gap \\
\hline D4 Mattress & 185 & post-expos. flames thru mattress side; barrier gap on top \\
\hline D4 Mattress & 240 & post-exposure flames penetrated matt side by convoluted path \\
\hline $\begin{array}{c}\text { D4 Mattress } \\
\text { With Vertical Seam } \\
\end{array}$ & No Burn Through & $\begin{array}{l}\text { PU foam layer extended from top onto mattress side; } \\
\text { all flames out at } 6 \text { min } 26 \mathrm{~s} \text {; smoke/smol. until } 10 \text { min } 16 \mathrm{~s}\end{array}$ \\
\hline D4 Foundation $^{3}$ & 25 & penetration through both seam and shoddy pad \\
\hline D4 Foundation & 76 & post-exposure flames penetrated fdn top \\
\hline D4 Foundation & No Burn Through & all flaming out at 4 min $33 \mathrm{~s}$; smoke/smol. until ca. $10 \mathrm{~min}$ \\
\hline $\begin{array}{r}\text { D4 Foundation } \\
\text { With Vertical Seam }\end{array}$ & No Burn Through & all flaming out at 3 min $28 \mathrm{~s}$; smoke/smol. until 16 min $32 \mathrm{~s}$ \\
\hline
\end{tabular}

\footnotetext{
${ }^{25}$ Burner exposure, in all cases, was 70 seconds. $\quad \quad{ }^{3}$ Shoddy pad extends over foundation top and sides in this design, at least on portion tested
} 
Table 6, Cont'd. Summary of Composite Bench-Scale Test Results for D Series

\begin{tabular}{|c|c|c|}
\hline Matt/Fdn Design & Time to Any Burn-Through (s) & Comment \\
\hline D5 Mattress & No Burn Through & all flames out at 4 min $9 \mathrm{~s}$; smoke/smol. until 5 min $29 \mathrm{~s}$ \\
\hline D5 Mattress & $(100 \mathrm{~s})$ & post-exposure burn through was probably a frame bypass \\
\hline D5 Mattress & No Burn Through & all flames out at $4 \mathrm{~min} 17 \mathrm{~s}$; smoke/smol. until $5 \min 28 \mathrm{~s}$ \\
\hline $\begin{array}{c}\text { D5 Mattress } \\
\text { With Vertical Seam }\end{array}$ & $(320)$ & post-exposure burn through was probably a frame bypass \\
\hline D5 Foundation $^{4}$ & $(62)$ & burner flames apparently penetrated fdn top barrier \\
\hline D5 Foundation & $(91)$ & post-exposure flames apparently penetrated fdn top barrier \\
\hline D5 Foundation & No Burn Through & all flames out at 3 min $29 \mathrm{~s}$; smoke/smol. until ca. 4 min \\
\hline $\begin{array}{c}\text { D5 Foundation } \\
\text { With Vertical Seam } \\
\end{array}$ & No Burn Through & $\begin{array}{c}\text { all flames out at } 5 \text { min } 30 \mathrm{~s} \text {; smoke/smol. until } 6 \text { min } 38 \mathrm{~s} \text {; } \\
\text { vertical seam showed partial separation }\end{array}$ \\
\hline & & \\
\hline D6 Mattress & $(125)$ & post-exposure flames penetrated around short side panel \\
\hline D6 Mattress & No Burn Through & all flames out at $5 \mathrm{~min} 40 \mathrm{~s}$; smoke/smol. to at least $30 \mathrm{~min}$ \\
\hline D6 Mattress & No Burn Through & all flames out at 6 min $45 \mathrm{~s}$; smoke/smol. until 16 min $26 \mathrm{~s}$ \\
\hline $\begin{array}{c}\text { D6 Mattress } \\
\text { With Vertical Seam }\end{array}$ & No Burn Through & all flames out at 5 min $23 \mathrm{~s}$; smoke/smol. until 6 min $40 \mathrm{~s}$ \\
\hline D6 Foundation & No Burn Through & all flames out at 4 min $1 \mathrm{~s}$; smoke/smol. until ca. 8 min \\
\hline D6 Foundation & No Burn Through & all flames out at 3 min $13 \mathrm{~s}$; smoke/smol. until $10 \min 15 \mathrm{~s}$ \\
\hline D6 Foundation & $(20)$ & flames penetrated past short side barrier \\
\hline $\begin{array}{r}\text { D6 Foundation } \\
\text { With Vertical Seam }\end{array}$ & No Burn Through & all flames out at 7 min $15 \mathrm{~s}$; smoke/smol. until $11 \min 18 \mathrm{~s}$ \\
\hline
\end{tabular}

\footnotetext{
${ }^{4}$ Shoddy pad extends under both fdn top and sides for this design, at least for portion
} 


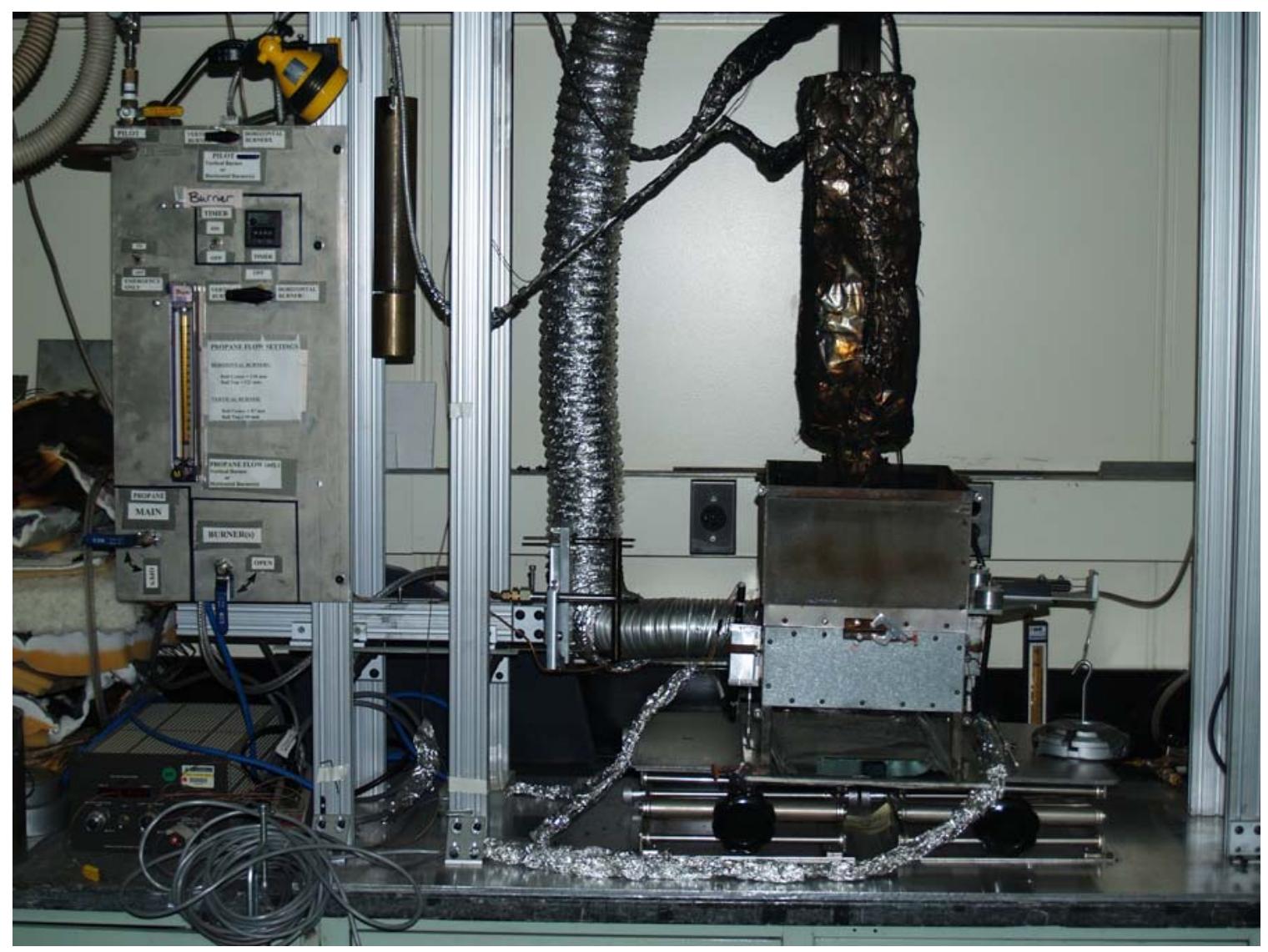

Figure 1. Overview of gas burner exposure apparatus. The propane gas control panel is at the left. Immediately to its right, between the two vertical structural beams, is the counterweight for the gas burner assembly to control the downward force the burner exerts on the sample top. The sample itself is in the bottom of the upper, dark gray section of the box to the right of center. The double gas burner is at the base of the dark rectangular, foil covered object above the sample box; it rides on a vertical rail within the foil covered area. 


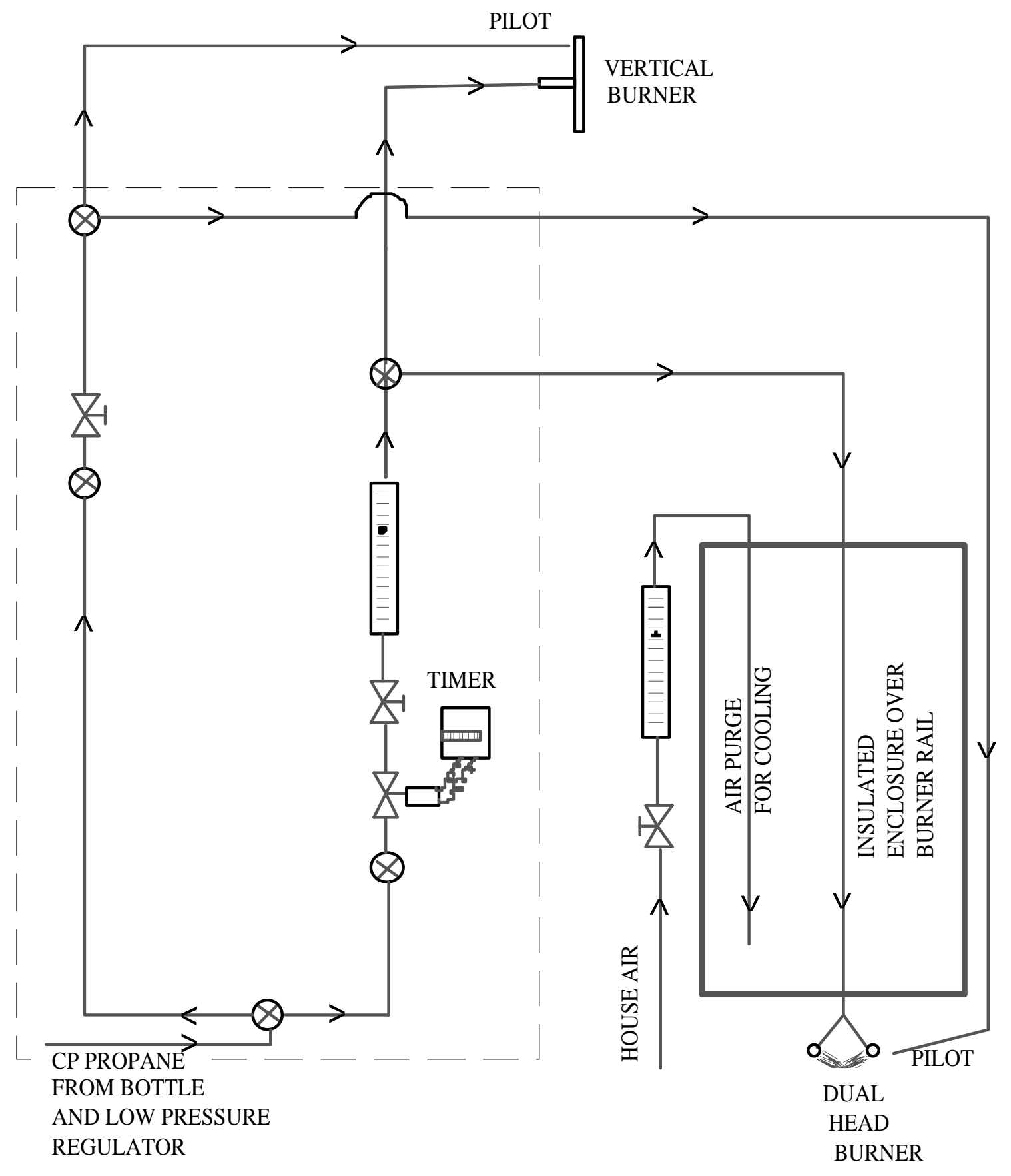

FIGURE 2. SCHEMATIC OF GAS CONTROL SYSTEM 
Figure 3

Transverse Scan of Horizontal Burner Pair Approximately $2.5 \mathrm{~cm}$ Left of Center of Tee Heads

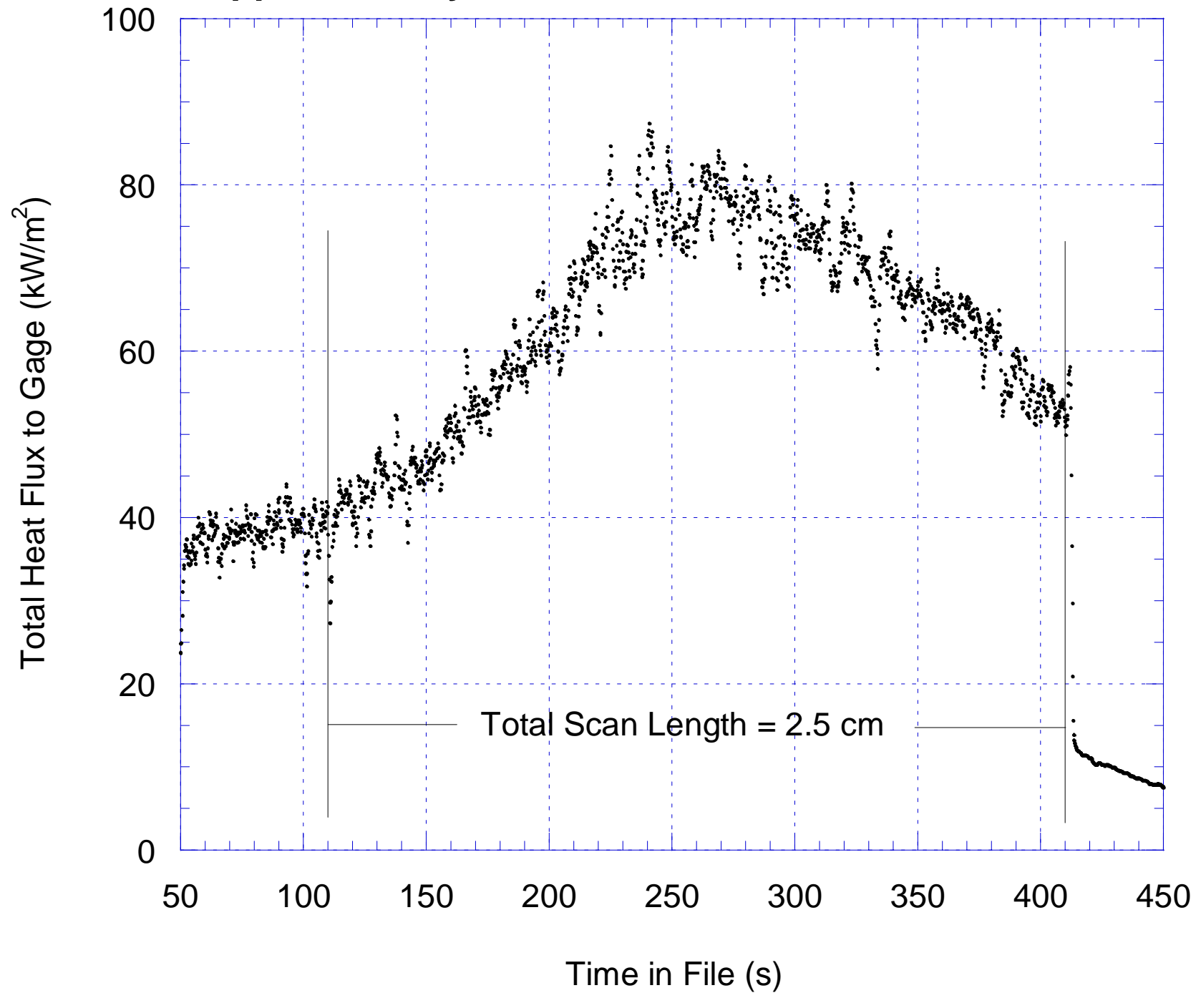




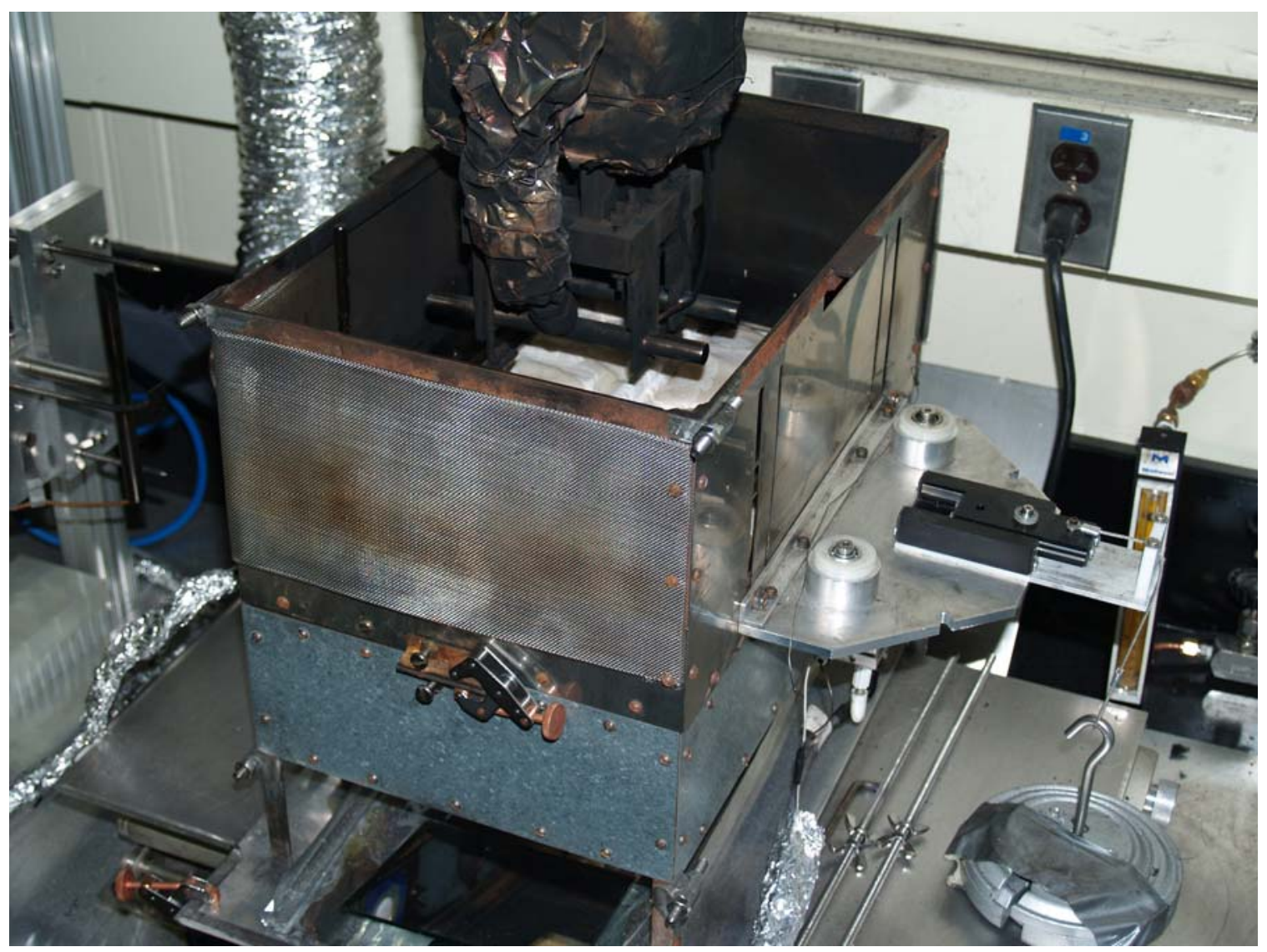

Figure 4a. Close-up of sample holder and double gas burner. Note that three of the four walls of the sample box are made of air permeable stainless steel wire mesh. The fourth wall, on the right, holds the apparatus for applying a uniform tension in the plane of the top of the sample by means of the weight seen in the lower right. One of the photocells for sensing flame penetration of the sample is immediately below the apparatus for applying the tension and is hidden by it in this view. 


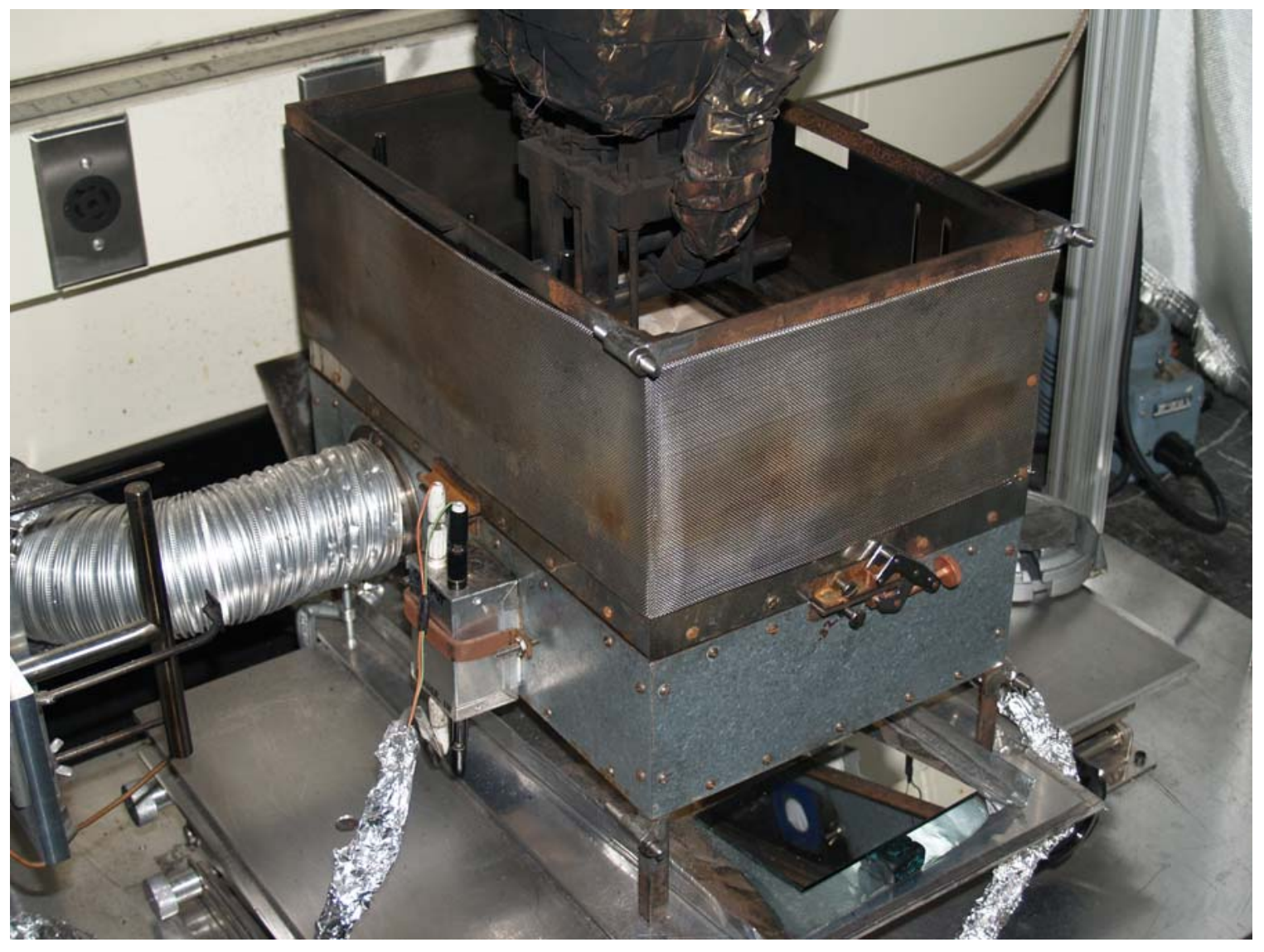

Figure 4b. View of the sample box. The lower part of the box is vented through the flexible duct to the left of center. The second photocell used to sense flame penetration of the sample is box next to the vent. The mirror for seeing the underside of the sample is visible on the lower right. The vertical burner used in the earliest versions of this test protocol is visible at the left, in front of the vent duct. 


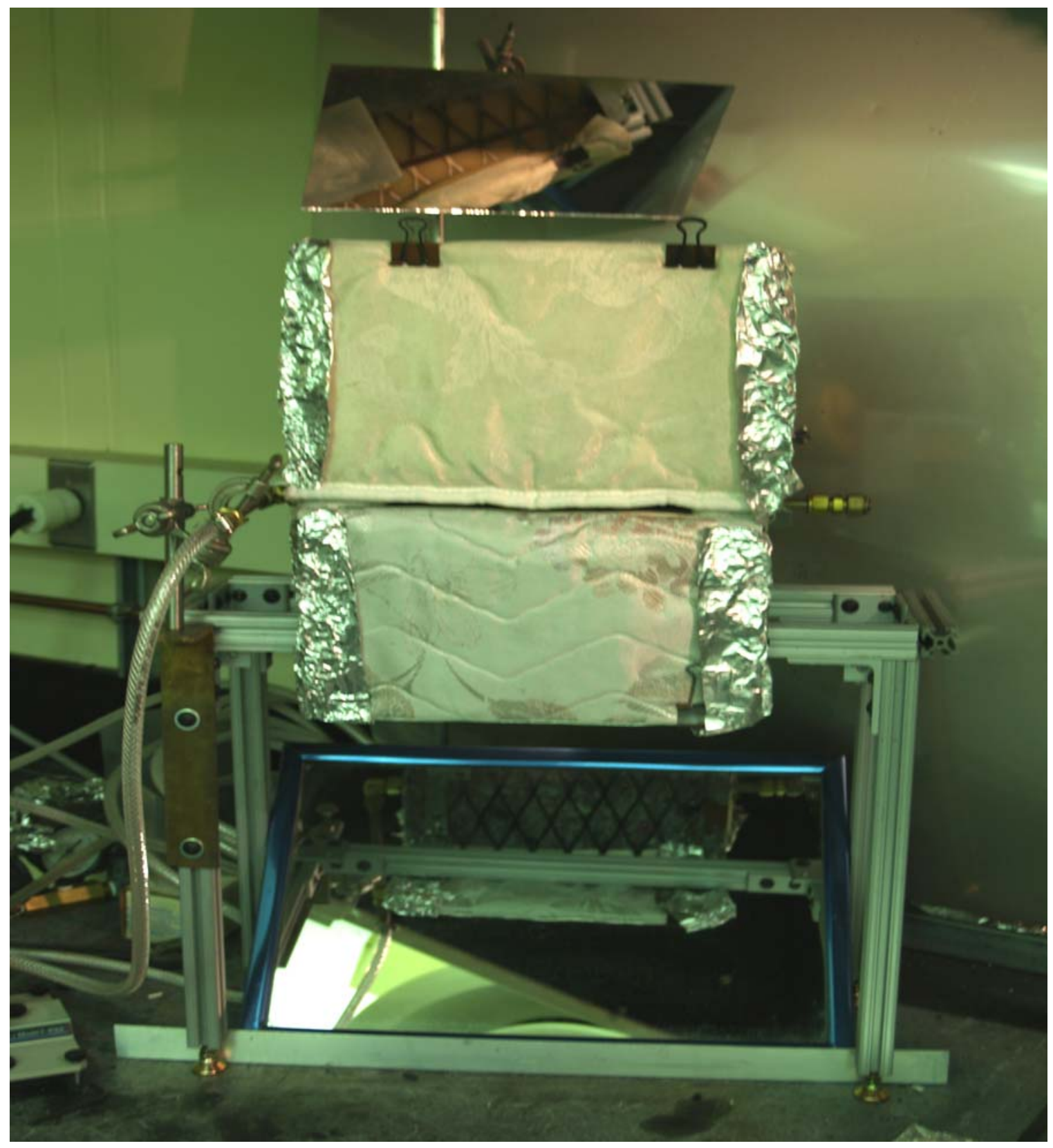

Figure 5. Overview of the crevice test apparatus. The mattress side panel is seen on top with the foundation side panel beneath it. Only the ends of the propane burner are visible protruding from each side of the mattress/foundation crevice. The mirrors giving the operator a view of the "interior" surfaces of the test pieces are evident above and below the sample 
Figure 6

Full Scale Tests of SPSC Beds With Gas Burners (Arranged in Order of Avg Peak HRR)

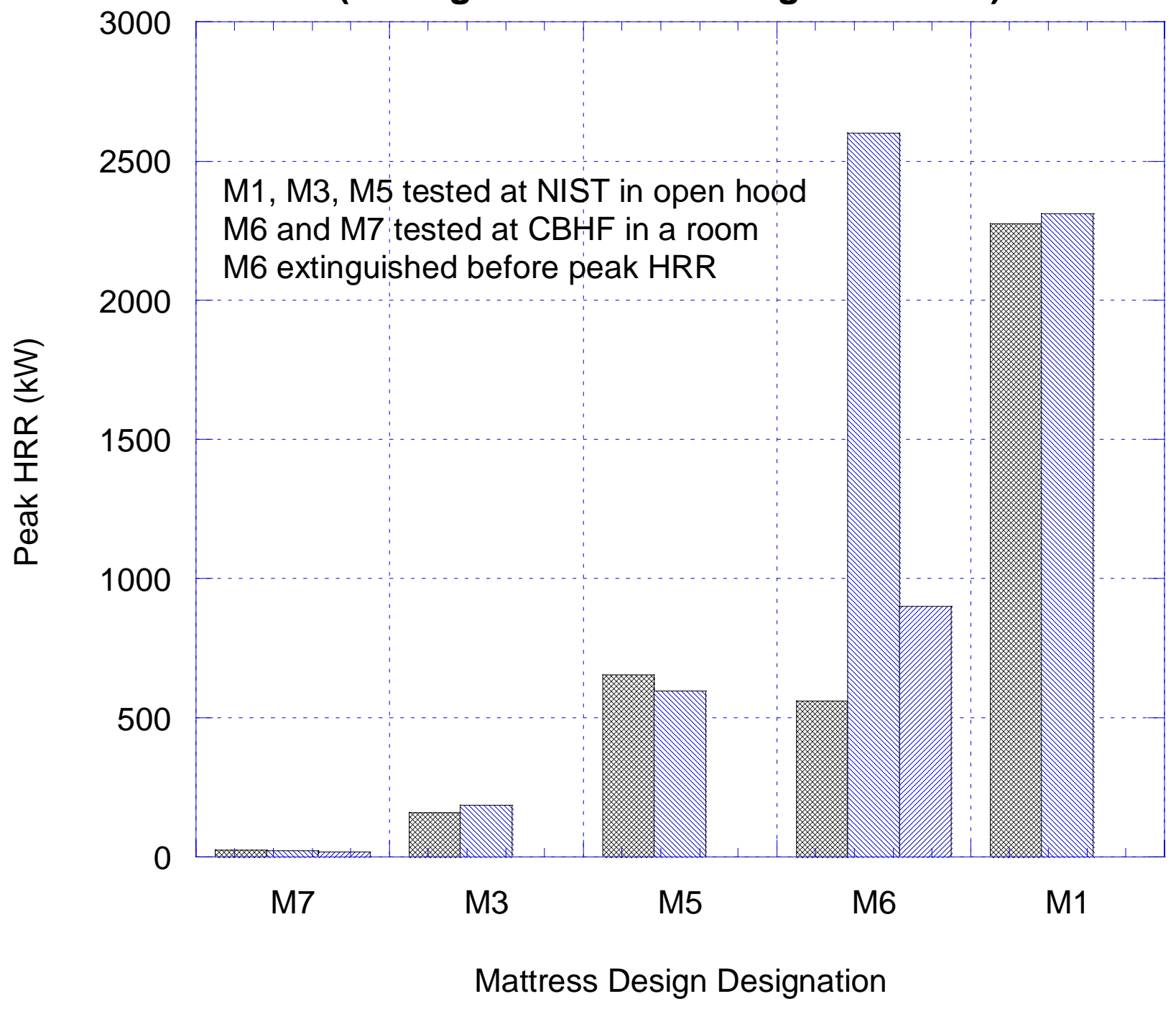


Figure 7

Full Scale Tests of CPSC Beds With Gas Burners (Arranged in Order of Average Peak Heat Release Rate)

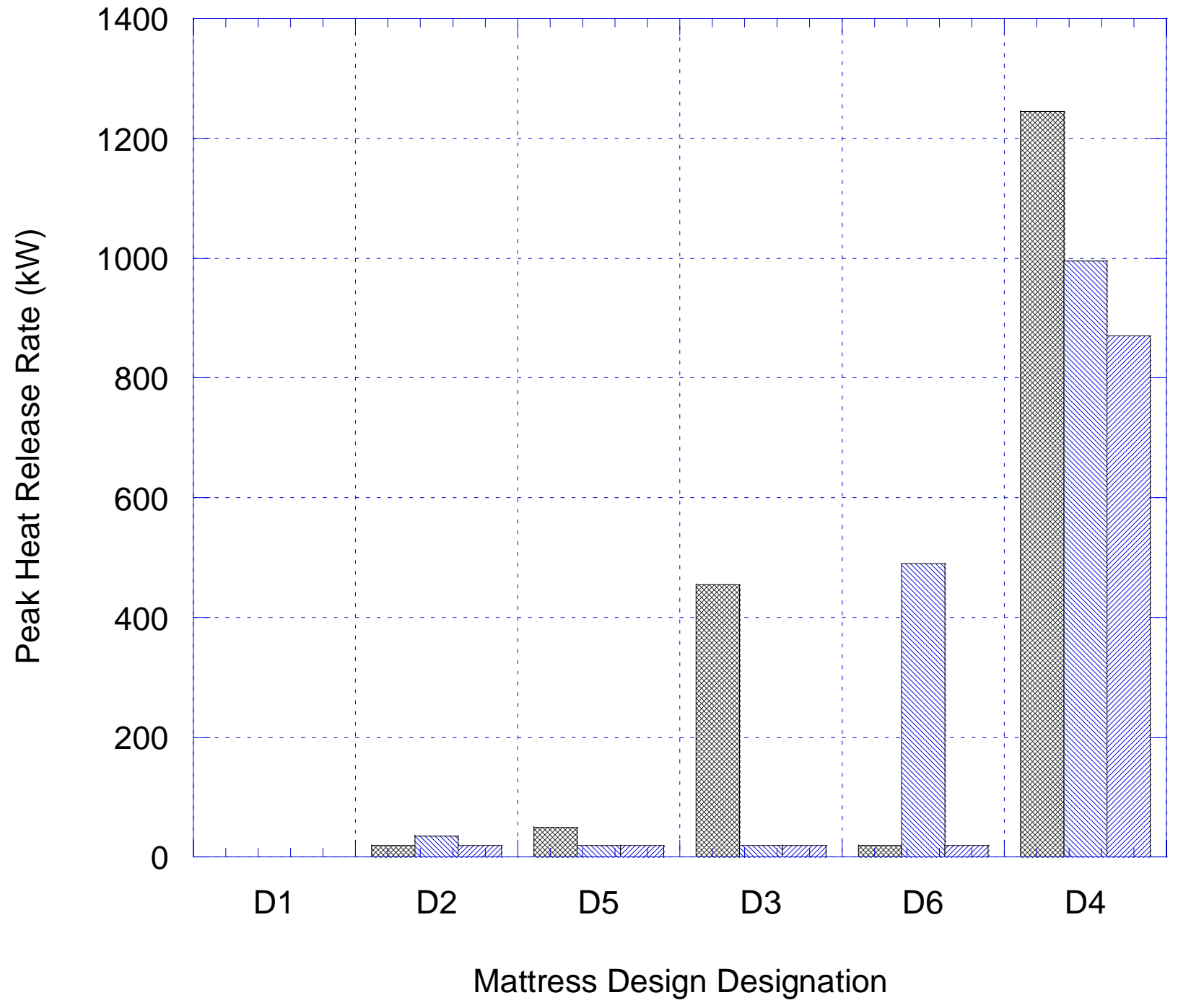


Figure 8

Bench-Scale Tests of SPSC Bed Designs

(Arranged in Order of Full Scale Peak HRR)

(Smallest to Largest)

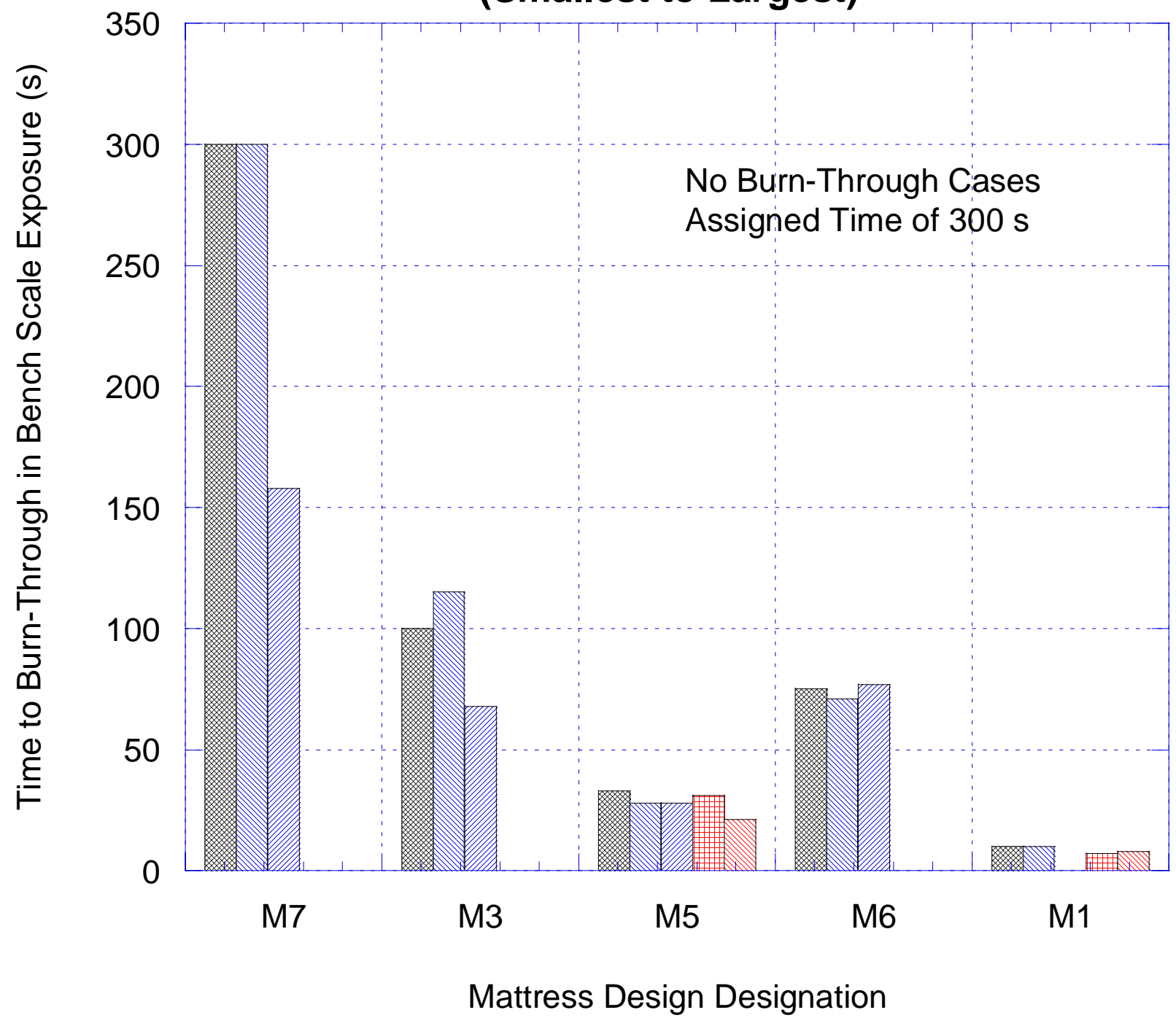

